\title{
Defective Postnatal Neurogenesis and Disorganization of the Rostral Migratory Stream in Absence of the Vax1 Homeobox Gene
}

\author{
José Miguel Soria, ${ }^{1}$ Paola Taglialatela, ${ }^{1}$ Sara Gil-Perotin, ${ }^{3}$ Rossella Galli, ${ }^{2}$ Angela Gritti, ${ }^{2}$ José Manuel Garcia Verdugo, ${ }^{3}$ \\ and Stefano Bertuzzi ${ }^{1}$ \\ 'Dulbecco Telethon Institute at Consiglio Nazionale delle Ricerche-Istituto di Tecnologie Biomediche, 20090 Segrate (Milan), Italy, 2 Stem Cell Research \\ Institute, Department of Biological and Technological Research, San Raffaele Hospital, 20132 Milan, Italy, and ${ }^{3}$ Instituto Cavanilles de Biodiversidad y \\ Biologia Evolutiva, University of Valencia, 46980 Valencia, Spain
}

The subventricular zone (SVZ) is one of the sources of adult neural stem cells (ANSCs) in the mouse brain. Precursor cells proliferate in the SVZ and migrate through the rostral migratory stream (RMS) to the olfactory bulb (OB), where they differentiate into granule and periglomerular cells. Few transcription factors are known to be responsible for regulating NSC proliferation, migration, and differentiation processes; even fewer have been found to be responsible for the organization of the SVZ and RMS. For this reason, we studied the ventral anterior homeobox ( Vax 1) gene in NSC proliferation and in SVZ organization. We found that Vax1 is strongly expressed in the SVZ and in the RMS and that, in the absence of Vax1, embryonic precursor cells proliferate 100 times more than wild-type controls, in vitro. The SVZ of $\operatorname{Vaxl}^{-/-}$brains is hyperplastic and mostly disorganized, and the RMS is missing, causing a failure of precursor cell migration to the OBs, which as a result are severely hypoplastic. Moreover, we found that $\operatorname{Vax} 1$ is essential for the correct differentiation of ependyma and astrocytes.

Together, these data indicate that $\operatorname{Vaxl}$ is a potent regulator of SVZ organization and NSC proliferation, with important consequences on postnatal neurogenesis.

Key words: subventricular zone; rostral migratory stream; neural stem cells; homeobox; development; telencephalon

\section{Introduction}

The telencephalic subventricular zone (SVZ) is the main source of adult neural stem cells (ANSCs) in rodents, generating olfactory bulb (OB) neurons (Alvarez-Buylla et al., 2001; Doetsch and Scharff, 2001; Kornack and Rakic, 2001; Pencea et al., 2001; Doetsch, 2003). The SVZ consists of a thin layer of cells in active proliferation throughout adulthood, covering the walls of the lateral ventricles (Doetsch et al., 1999; Johansson et al., 1999). In the postnatal brain, in direct contact with the lumen of the ventricle, are the multiciliated ependyma, marked by Noggin. In close contact with the ependyma is a special population of astrocytes

Received Aug. 7, 2004; revised 0ct. 22, 2004; accepted Nov. 1, 2004.

This work was supported by grants to S.B. from the Italian Telethon Foundation (GGP030245), Italian Ministry of Research, Fondo di Investimenti della Ricerca di Base (RBNE01YRA3_002), and Istituto Superiore di Sanitá (CS108.1).P.T. was supported by Newron Pharmaceuticals, to which we are deeply grateful. J.M.G.V. was supported by Grant SAF 03229 from the Ministry of Science and Technology of Spain, and S.G.-P. was supported by the Fondo de Investigación Sanitaria Instituto de Salud Carlos III Madrid (Exp. 01/9513). We are grateful to the following for providing us markers: Silvia Arber (Er81), Giorgio Merlo (Dlx1), and Regeneron Pharmaceuticals Inc. (Noggin). We thank Ferdinando Rossi and Giorgio Merlo for providing us $\beta$-actin-GFP mice. We thank Monique Dubois-Dalcq, Sandro Banfi, and Giorgio Merlo for critical reading of this manuscript and Ramil Libat for excellent technical assistance.

Correspondence should be addressed to Dr. Stefano Bertuzzi, Dulbecco Telethon Institute at Consiglio Nazionale delle Ricerche-Istituto di Tecnologie Biomediche, Via Fratelli Cervi 93, 20090 Segrate (Milan), Italy. E-mail: sbertuzzi@dti.telethon.it.

DOI:10.1523/JNEUROSCI.3248-04.2004

Copyright $\odot 2004$ Society for Neuroscience $\quad$ 0270-6474/04/2411171-11\$15.00/0
(B-cells), labeled by Nestin, glial fibrillary acidic protein (GFAP), and vimentin (Doetsch et al., 1999). B-cells are the in vivo bona fide ANSCs (Doetsch et al., 1999) and randomly extend protrusions intercalating with ependymal cells. Besides symmetric divisions, B-cells generate a transit amplifying population of cells (C-cells) that expresses Nestin, Dlx2, and Dlx1 (Doetsch et al., 1999; Saino-Saito et al., 2003). C-cells give rise to a third type of precursor, the migrating neuroblasts (A-cells), which express TUJ1, DLX2, DLX1, and polysialylated-neural cell adhesion molecule (Miragall et al., 1990; Bonfanti and Theodosis, 1994; Ben-Hur et al., 1998; Saino-Saito et al., 2003). These cells delaminate in the anterior SVZ (SVZa) and migrate toward the OB at $\sim 30 \mu \mathrm{m} / \mathrm{hr}$, through chain migration (Lois et al., 1996; GarciaVerdugo et al., 1998). The anterior migration of neuroblasts generates a protrusion of the SVZ called the rostral migratory stream (RMS) (Altman, 1969).

Little is known about the genetic determinants that regulate proliferation and differentiation of the SVZ (for review, see Doetsch, 2003; Alvarez-Buylla and Lim, 2004). By perturbing Emx2 expression in cultured SVZ precursors, it was shown that $E m \times 2$ regulates the proliferation of multipotent NSCs in a negative manner, likely by diminishing their capacity for selfmaintenance (Galli et al., 2002). Given the role for Emx2 in SVZ proliferation, in this work we focused our attention on the function of Vax1, a homeobox gene evolutionary related to Emx2 
(Hallonet et al., 1998, 1999; Bertuzzi et al., 1999; Taglialatela et al., 2004).

We show that (1) Vaxl is expressed in the developing and postnatal SVZ and RMS; (2) in Vax1 mutant brains, the SVZ is significantly hyperplastic; (3) the differentiation and the consequent migration of precursor cells from the SVZ to the $\mathrm{OB}$ is impaired; (4) the OBs are depleted of periglomerular neurons and are severely hypoplastic; (5) in neurosphere culture assays, cells lacking a functional $\operatorname{Vax} 1$ gene product hyperproliferate at a rate 100-fold higher than the wild-type (WT) counterparts if cultures are established from embryonic day 15.5 (E15.5) SVZ, whereas they proliferate at the same rate as wild type if derived from postnatal day 0 (P0) SVZ; (6) ependymal cells and astrocytes do not differentiate correctly, compromising the anatomical structure of the RMS and the SVZ neurogenic niche; and, finally, (7) $\mathrm{Vax1}^{-/-} \mathrm{SVZ}$ precursors are capable of migration to the $\mathrm{OB}$ in a WT environment.

\section{Materials and Methods}

Mutant mice

Vax $1^{-1-}$ mice die at birth because of a severe cleft palate (Bertuzzi et al., 1999; Hallonet et al., 1999), however $6 \%$ of $\operatorname{Vaxl}^{-/-}$mice live up to 3 weeks of age. This study has mainly focused on these rare survivors $(n=$ 15), because it was possible to study the postnatal SVZ and RMS. $\mathrm{Vaxl}^{-1-}$ embryos were generated by crossing heterozygous mice on a $129 \mathrm{SV} \times$ C57BL/6 background. Genotyping was performed by PCR. Embryos were obtained from pregnant females at various stages of development. Noon of the day when the vaginal plug was identified was considered as E0.5, and embryos were subsequently staged according to morphological criteria and processed as described previously (Taglialatela et al., 2004).

\section{Electron microscopy}

P0 $(n=6)$ and P15 $(n=2)$ WT mice and $\operatorname{Vaxl}^{-/-}$littermates were anesthetized and perfused transcardially with $100 \mathrm{ml}$ of Karnovsky's fixative [2\% paraformaldehyde (PFA) and 2.5\% glutaraldehyde]. Electron microscopy was performed as described previously (Doetsch et al., 1997). Cells in the ventricular zone were classified as multiciliated ependymal cells if they matched two or more of the maturation criteria: (1) presence of more than one cilium; (2) presence of more than one basal body; (3) presence of electron-dense aggregates; and (4) presence of few cytosolic organella. Immature uniciliated ependymal cells were identified following these criteria: (1) presence of an abundant endoplasmic reticulum; (2) presence of a single cilium; and (3) presence of a centriole perpendicular to the basal body (Tramontin et al., 2003).

Astrocytes in the SVZ were identified according to ultrastructural criteria (Doetsch et al., 1997). The area and perimeter of the nucleus of 30 astrocytes for each genotype was quantified using IMAGE BETA 4.0.2 software (Scion, Frederick, MD).

\section{In situ RNA hybridization}

In situ hybridization was performed on frozen sections with digoxigeninlabeled probes, as described previously (Taglialatela et al., 2004). Reactive tissues were revealed by incubation with the alkaline phosphatase substrate BM-Purple (Roche).

\section{Immunohistochemistry}

Tissue sections were postfixed in 4\% PFA for $5 \mathrm{~min}$, rinsed in PBS, and blocked in $10 \%$ normal goat serum/0.1\% Triton X-100 at room temperature for $1 \mathrm{hr}$. The following antibodies were incubated overnight in $0.1 \%$ normal goat serum and $0.1 \%$ Triton $\mathrm{X}-100$ at $4^{\circ} \mathrm{C}$ : rat anti-mouse KI-67 (catalog\#M7249; 1:100; Dako, High Wycombe, UK), anti-tyrosine hydroxylase (TH) (catalog \#T1299; 1:10,000; Sigma, St. Louis, MO), anti-GFAP (catalog \#G-3893; 1:10,000; Sigma), anti-neural class III $\beta$-tubulin (catalog \#MM-S405-P; 1:500; Babco, Richmond, CA), rabbit polyclonal anti-ER81 (1:1000; generous gift from Dr. S. Arber, Biozentrum, University of Basel, Switzerland), anti-caspase III (1:500; Idun Pharmaceutical), anti-GABA (catalog \#A2052; 1:1000; Sigma), anti- neuron-specific nuclear protein (NeuN) (catalog \#MAB377B; 1.100; Chemicon, Temecula, CA), and anti-bromodeoxyuridine (BrdU) (cata$\log$ \#B2531; 1:100; Sigma). Anti-KI-67 staining was performed after heat induction epitope retrieval in $10 \mathrm{mmol} / \mathrm{l}$ citrate buffer, $\mathrm{pH} 6$.

Sections were incubated for $1 \mathrm{hr}$ with biotinylated secondary antibodies: goat anti-rabbit (1:100; Jackson ImmunoResearch, West Grove, PA), goat anti-mouse (1:100; Jackson ImmunoResearch), or donkey anti-rat (1:500; Jackson ImmunoResearch). Subsequently, tissues were incubated for 30 min with an avidin-biotin-peroxidase complex (Elite PK-6100; Vector Laboratories, Burlingame, CA) and revealed with DAB peroxidase substrate (SK-4100; Vector Laboratories). For fluorescent immunohistochemistry, sections were incubated for $1 \mathrm{hr}$ with goat anti-mousecyanine 3 and goat anti-rabbit-FITC (1:100; Jackson ImmunoResearch). Terminal deoxynucleotidyl transferase-mediated biotinylated UTP nick end labeling (TUNEL) histochemistry assay was performed using an ApopTag Plus Fluorescein apoptosis detection kit (catalog \#S7111; Intergen, Purchase, NY).

\section{Organotypic slice cultures}

Analysis of cell migration by $1,1^{\prime}$-dyoctodecyl-3,3,3',3'-tetramethylindocarbocyanine labeling. Experiments were performed as described previously (Taglialatela et al., 2004). To trace the migratory pathway of neurons from the lateral ganglionic eminence (LGE) to the OB, we placed small crystals of 1,1'-dyoctodecyl-3,3,3',3'-tetramethylindocarbocyanine (DiI) (Molecular Probes, Eugene, OR), or a piece of bamboo soaked in DiI, in the region of interest. Cultures were incubated for $48 \mathrm{hr}$ in Neurobasal medium as described previously, subsequently fixed in $4 \%$ PFA for $1 \mathrm{hr}$, and examined by fluorescence microscopy.

Tissue transplantation in vitro. We crossbred transgenic $\beta$-actin-green fluorescent protein $\left(\beta\right.$-actin-GFP $\left.{ }^{+/-}\right)$mice (Okabe et al., 1997) with $\operatorname{Vaxl}^{+/-} ; \mathrm{GFP}^{-/-}$mice. The offspring bearing the genotypes $\operatorname{Vaxl}^{+/+}$; $\mathrm{GFP}^{+/-}$and $\mathrm{Vaxl}^{-1-} ; \mathrm{GFP}^{+/-}$were selected and used as donors of GFPlabeled progenitor cells. P0 $\mathrm{Vaxl}^{+/+} ; \mathrm{GFP}^{-/-}$and $\mathrm{P} 0 \mathrm{Vaxl}^{-/-} ; \mathrm{GFP}^{-/-}$ mice were used as receivers for the transplant. Dissected brains were included and sectioned sagittally using a vibratome. Slices were collected in a Petri dish filled with $0.1 \mathrm{M}$ PBS and $0.6 \%$ glucose at $4^{\circ} \mathrm{C}$. Selected slices were placed on Millicell CM membranes, where the region of interest (SVZ) was carefully dissected from the donor slice (using a glass microneedle) and transplanted into a comparable host section at the level of the SVZa. Cultures were incubated for $1 \mathrm{hr}$ with DMEM/F-12, 6.5 $\mathrm{mg} / \mathrm{ml}$ glucose, $0.1 \mathrm{~mm}$ glutamine, $50 \mathrm{mg} / \mathrm{ml}$ penicillin-streptomycin, and $10 \%$ FCS and subsequently incubated for $2 \mathrm{~d}$ in Neurobasal medium supplemented with B27. After rinsing in PBS, slices were fixed. Migrating GFP-positive cells were analyzed by confocal microscopy (MRC-1024; Bio-Rad, Hercules, CA).

\section{DiI tracing}

Normal and $\mathrm{Vaxl}^{-1-}$ postnatal mice were anesthetized and perfused transcardially with $4 \%$ PFA. A small volume of DiI solution $(3 \mathrm{mg} / \mathrm{ml}$, dissolved in DMSO) was injected carefully into the nasal cavities using a glass microneedle. Immediately after the injection, the nasal cavities were sealed with $2 \%$ PFA-2\% agarose. The tissue was protected from the light and kept for 3 weeks in semisolid 2\% PFA-2\% agarose at room temperature. Serial $100-150 \mu \mathrm{m}$ vibratome sections were cut in a sagittal plane and examined by fluorescence microscopy.

\section{Neurosphere assays}

NSC cultures were established as described previously (Reynolds and Weiss, 1992; Gritti et al., 1999; Galli et al., 2002). Tissues obtained from WT and $\operatorname{Vaxl}^{-/-}$mouse LGE at E15.5 and P0 were mechanically dissociated with a fire-polished Pasteur pipette, and single-cell suspensions were plated in DMEM/F-12 basal medium in the presence of epidermal growth factor (EGF) and FGF2. Separate cell lines were established from single embryos, and their genotype was confirmed by DNA-PCR. For population analysis, cells were plated at $8000 \mathrm{cells} / \mathrm{cm}^{2}$, and the formed spheres were collected and dissociated every $3 \mathrm{~d}$. The total number of viable cells was assessed at each passage by trypan blue (Sigma) exclusion.

\section{In vivo birthdating analysis}

Experiments were performed as described previously (Taglialatela et al., 2004). Pregnant mothers and early postnatal mice were given intraperi- 

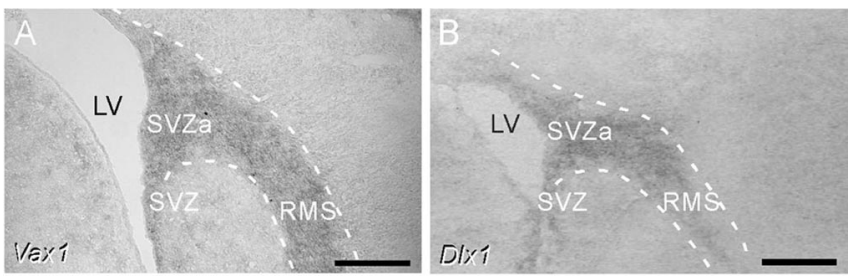

Figure 1. Vax1 expression in the SVZ and RMS. A, In situ hybridization revealing widespread Vax1 expression within the WT telencephalic SVZ, SVZa, and RMS at P20 (sagittal cutting plane). Scale bar, $500 \mu \mathrm{m}$. B, In situ hybridization revealing DIx1 expression in the SVZ, SVZa, and RMS at P20. D/x1 labels transit amplifying cells (C-cells) and migrating neuroblasts (A-cells). Scale bar, $200 \mu \mathrm{m}$. LV, Lateral ventricle.

toneal injections of a dose of $100 \mathrm{mg}$ of $\mathrm{BrdU} / \mathrm{gm}$ of body weight. Animals were anesthetized and perfused transcardially with 4\% PFA in $0.1 \mathrm{M}$ PBS.

\section{Determination of cell cycle length by BrdU incorporation}

WT as well as mutant-derived stem cells were plated at a cell density of 30,000 cells $/ \mathrm{cm}^{2}$ on $10 \mathrm{~mm}$ Matrigel-coated glass coverslips in neurospheres-A medium containing $1 \mu \mathrm{M} \mathrm{BrdU}$ (Roche) for up to $54 \mathrm{hr}$. Cells were fixed in 4\% PFA and stained with a monoclonal anti-BrdU antibody (ready to use; Amersham Biosciences, Piscataway, NJ). Nuclei were labeled with 4',6-diamidino-2-phenylindole (DAPI). One thousand cells (identified by DAPI staining) were counted per coverslip. The relative labeling index (LI) was plotted against the BrdU labeling time to obtain an S phase cumulative labeling curve (Tang et al., 2000). $L I(t)$ and the correlation index $r$ were determined in the linearity interval by linear regression methods. Using the formula $y=a x+b$, we determined $T c=1 / L I(t)$.

Determination of cell viability by 3-(4,5-dimethylthiazol-2-yl)2,5-diphenyl-2H-tetrazolium bromide assay

Cells were plated onto Matrigel-coated 96-well plates (10,000 cells/well). At every time point, $1 \mathrm{hr}$ before collection, the tetrazolium dye 3-(4,5dimethylthiazol-2-yl)-2,5-diphenyl-2 $H$-tetrazolium bromide (MTT) (5 $\mathrm{mg} / \mathrm{ml}$ in PBS; Sigma) was added to the medium (final dilution, 500 $\mu \mathrm{g} / \mathrm{ml}$ ). The pale yellow redox indicator MTT is reduced to a dark blue end product, MTT-formazan, by the mitochondrial dehydrogenases of living cells. After a $1 \mathrm{hr}$ incubation at $37^{\circ} \mathrm{C}$, the medium was discarded, and cells were lysed by adding $50 \mu \mathrm{l}$ of DMSO. After $15 \mathrm{~min}$ at room temperature, MTT reduction was measured spectrophotometrically at a wavelength of $550 \mathrm{~nm}$.

\section{Results}

\section{Vax1 is expressed in the postnatal SVZ and RMS}

We have recently shown that during development, $\operatorname{Vax} 1$ is expressed in the SVZ of the subcortical telencephalon (Hallonet et al., 1998; Taglialatela et al., 2004). We have now studied Vax1 expression in the SVZ of the postnatal brain, a stage at which Vax1 expression has never been reported before. Interestingly, Vax 1 expression is readily detected by in situ hybridization and is highly restricted to the two neurogenic areas of the postnatal brain, the SVZ and the hippocampus (Fig. 1) (data not shown), where it is also maintained throughout adulthood (data not shown). P20 Vax1 is strongly expressed in a thin layer of cells in the periventricular area of the SVZ and in the RMS (Fig. 1A,B). The cellular composition and the cytoarchitecture of the SVZ and RMS are well characterized at the ultrastructural level and are known to contain different cell types, as described in Introduction. As shown in Figure $1 A$, the expression of Vax1 in the SVZ and RMS seems rather homogeneous, possibly indicating that Vax 1 expression is not restricted to a particular cell type. Here we focus on the role of Vax1 in the young adult telencephalic SVZ.
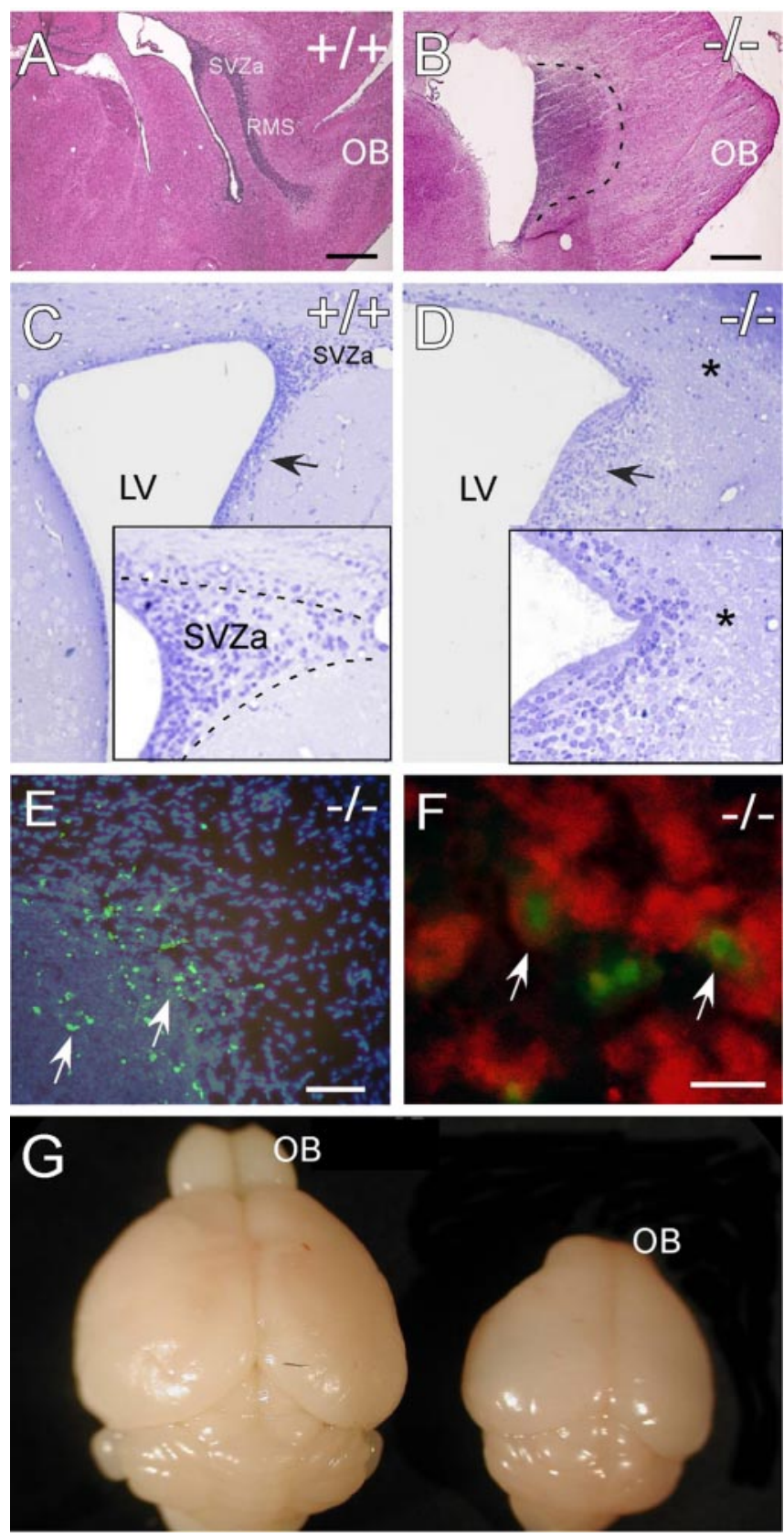

Figure2. Abnormal differentiation of the SVZ in $\operatorname{Vax}^{-/-}$mice. $A, B$, Hematoxylin and eosin staining of WT and $\mathrm{Vax}^{-/-}$mutant sagittal sections at P15. Note the expansion of the SVZ in the mutants. C, In WT brains at P15, the SVZa contains precursor cells delaminating from the SVZ and entering the RMS. D, In P15 Vax1 ${ }^{-1-}$ brains, it is not possible to detect a defined SVZa. The insets show in detail the SVZa anatomy in WT ( $C$ and $\operatorname{Vax} 1(D)$ mutants. E, Apoptotic cells were detected by TUNEL assay in the mutant SVZ (green signal and arrows). F, Many of the apoptotic cells shown in E, identified here by caspase-3 staining, colocalized with neuronal precursor cells (Tuj1 positive; arrows). G, Dorsal view of P15 WT (left) and KO (right) brains. Note the hypoplastic $\operatorname{Vax}^{-1-}$ OB. LV, Lateral ventricle. Scale bars: $A, B, E, 500 \mu \mathrm{m} ; F, 100 \mu \mathrm{m} ; G, H, 20 \mu \mathrm{m}$.

\section{The RMS is absent in $\operatorname{Vax1}^{-/-}$mice}

The RMS is a structure fully completed by P20 (Peretto et al., 1997, 1999; Law et al., 1999). We examined the RMS in these mice and found that it was greatly reduced, if not completely absent. Figure 2, $A$ and $B$, shows eosin- hematoxylin staining of a P20 Vax1 mutant brain in a sagittal orientation. As can be seen in the WT brain, the RMS is darkly labeled by the hematoxylin purple stain, displaying its characteristic sigmoid shape (Fig. 2A). However, in a corresponding section of a Vaxl mutant, the RMS is not 
organized (Fig. 2 B). In few mutants $(\sim 10 \%)$ it is possible to recognize a faint RMS, but in the vast majority of the brains that we have analyzed $(n=16)$, the RMS is missing altogether. It is evident from the observation of semithin sections (Fig. 2C,D) that the SVZa in WT brains has a characteristic triangular shape (Fig. 2C, inset). This area contains cells entering the RMS, in migration toward the OB; strikingly, in $\operatorname{Vax} 1$ mutants (Fig. 2D) the SVZa is absent (Fig. 2D, inset, asterisk). Moreover, the SVZ, instead of being a thin layer of cells expressing Vax1, consists of a thick layer of cells, darkly stained by toluidine blue coloration (Fig. 2C,D, arrows). These results indicate that in P20 Vax1 mutants there are fewer or no cells entering the RMS, despite the fact that there are more cells present in the SVZ. This suggests that in the Vax1 mutant brain, precursor cells are overproliferating, or failing to migrate, or perhaps both. Because the SVZ is thicker and overpopulated with precursor-looking cells, we wanted to understand whether aberrant apoptosis was present in this area (Fig. 2E,F). To this aim, we performed TUNEL staining and indeed detected an increased number (>90\%) of TUNELpositive cells compared with the WT brain. These apoptotic cells colocalized, at least in part, with the presence of TUJ1, a marker for migrating neuroblasts (Fig. $2 F$, arrows).

In summary, in the absence of a functional Vax1 gene product, we observed an expanded SVZ $(\sim 10$ times the normal size $)$ and a lack of RMS formation. We then addressed the consequences of this major defect on the $\mathrm{OB}$, which in $\operatorname{Vaxl}^{-/-}$mice appear severely hypoplastic (Fig. $2 G$ ).

\section{The OBs in $\operatorname{Vax1}^{-/-}$mice are severely hypoplastic}

In the OB, cells that migrate from the SVZ differentiate into granule and periglomerular cells and stain positive for TH (Fig. 3A) (Wichterle et al., 1997; Doetsch et al., 1999) [for a general organization of the OB, see Long et al. (2003)]. In WT mice at $\mathrm{P} 20$, TH staining reveals well formed glomeruli in the peripheral layers of the $\mathrm{OB}$ (Fig. $3 A$ ), whereas they are completely missing in the mutant $\mathrm{OB}$ (Fig. 3B). We considered that TH-positive cells in the $\mathrm{OB}$ are extremely sensitive to denervation and that they undergo rapid apoptosis if synapses with the olfactory nerve are lost (McLean and Shipley, 1988). Because Vax1 is also expressed in the olfactory epithelium (OE) (data not shown), we were concerned that the loss of TH-positive cells in the OB could be the result of a lack of olfactory innervation. To rule out this possibility, we injected the fluorescent tracer DiI in the OE of P0 Vax1 $1^{-1-}$ mice and allowed 3 weeks for the dye to reach the OB. As shown in Figure $3 E-H$, the innervation of the $\mathrm{OB}$ is maintained in $\operatorname{Vax} 1^{-/-}$brains, which clearly present axonal bundles that cross the lamina cribrosa making contact with the glomeruli in the $\mathrm{OB}$ (Fig. $3 H$, arrows). In $\operatorname{Vax}^{-/-}$mutants, the innervation of the $\mathrm{OB}$ is also maintained during postnatal stages: immunohistochemistry experiments using the olfactory marker protein as a marker of $\mathrm{OE}$ axons reveal innervation of the $\mathrm{OB}$ also at P20 (data not shown). It is worth noting that mitral cells, which differentiate in loco and stain positive for the surface molecule Reelin (Alcantara et al., 1998), are present in the mutant OB (Fig. 3D). However, we could detect fewer numbers of disorganized mitral cells in the Vax $1^{-/-}$OBs. We attribute this finding to a secondary defect caused by the loss of circuit organization in the mutant OB.

The population of ER81-positive precursor cells is dramatically expanded in the LGE of Vax1 mutants

As we have shown in Figure $2 A-D$, in the absence of Vax1, the SVZ is widely expanded, and at the ultrastructural level, it is evident that it is severely perturbed in the LGE portion (see be-
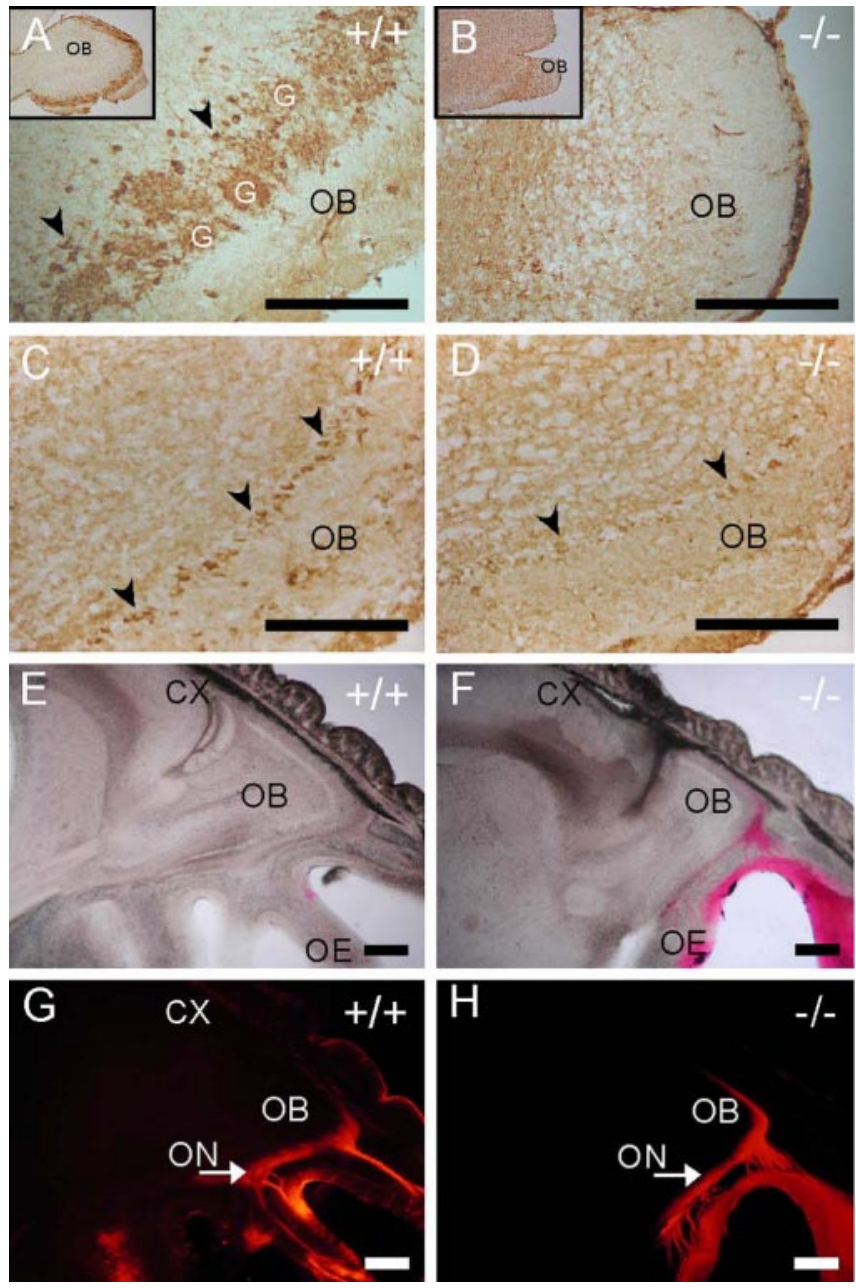

Figure 3. $\operatorname{Vax} 1^{-1-}$ OBs are severely hypoplastic, although correctly innervated. A, WT P2O $O B$ shows well organized glomeruli $(G)$, as revealed by TH staining. $B$, TH staining of the Vax ${ }^{-/-} O B$ shows the complete absence of periglomerular cells ( $A$, arrowheads). C, Mitral cells do not derive from migrating SVZ precursor cells and are immunoreactive for Reelin (arrowheads). $D$, The mitral cell layer is still present in the $\operatorname{Vax}^{-1-} \mathrm{OB}$, although disorganized (see Results). E-H, Dil tracing of the olfactory nerve. The olfactory nerve is evident in PO WT controls $(E, G)$ and in the Vax1 mutants $(F, H)$. All sections are in a sagittal orientation. $C X$, Cortex; $0 \mathrm{~N}$, olfactory nerve. Scale bars: $A, C, E-H, 500 \mu \mathrm{m} ; B, D, 200 \mu \mathrm{m}$.

low). We wanted to determine what type of precursor cells are involved in the SVZ expansion. Recently published work has demonstrated that the LGE contains two different populations of precursor cells (Stenman et al., 2003). In the ventral LGE, a pool of precursors labels positive for the lin-11 isl-1 mec-3 homedomain protein Islet-1 (ISL1) and is destined to become the projection neurons of the corpus striatum, whereas a second pool, located in the dorsal LGE, is positive for the Ets domain transcription factor ER81 and is fated to migrate through the RMS to generate granule and periglomerular cells of the OB. We were interested in this latter population of precursors, which we suspected could be affected in the Vax 1 mutant brain, given the hypoplasticity of the OB and the RMS defect. To our surprise, instead of a reduction in the ER81-positive cells, we detected a significant expansion of this population of cells at the expense of the ISL1 population, which is dramatically reduced at E15.5 (Fig. 4). At this stage, we also detected aberrant precursor cell hyperproliferation within the SVZ (Taglialatela et al., 2004).

At P0 in WT brains, the SVZ is a rather thin layer of cells protruding toward the OB, clearly labeled by the antibody anti- 

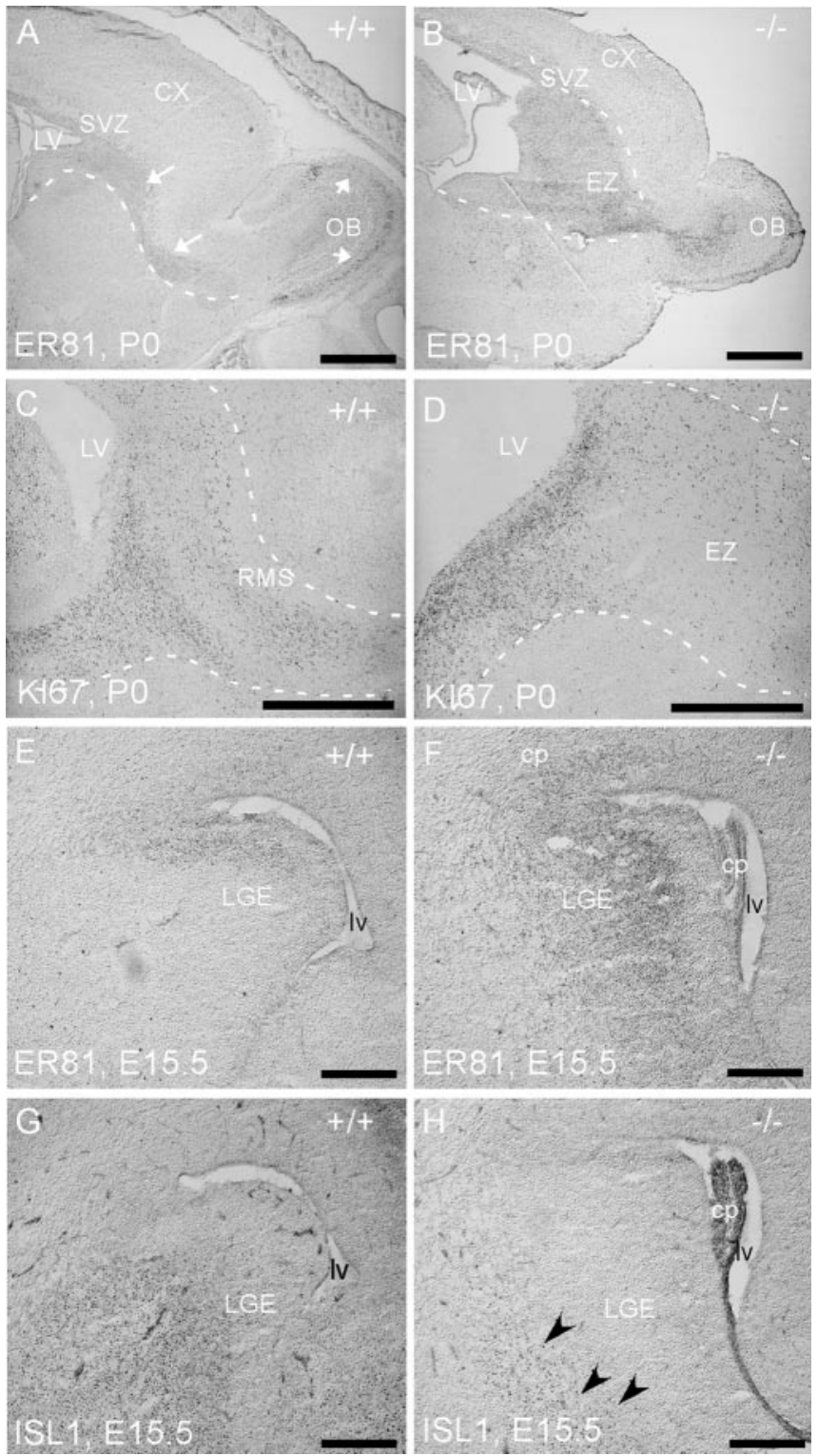

Figure 4. Vax1 mutants present an expanded SVZ, abnormally differentiated. $A, B$, Progenitor cells immunoreactive for the ETS transcription factor ER81 in the SVZ and in the OB of POWT $(A)$ and $\operatorname{Vax} 1(B)$ mutants. A, Arrows indicate ER81-positive cells in the SVZ, in the RMS (dashed line), and in the outermost layers of the $0 B$. In the absence of $\operatorname{Vax} 1(B)$, the SVZ appears mostly expanded, $\sim 10$ times the size of its WT counterpart, generating an expanded zone (EZ). C, D, Sagittal sections of PO WT ( $C$ and $\mathrm{Vax}^{-1-}(D)$ mutant telencephala analyzed by immunohistochemistry for the proliferation marker KI-67. In WT mice, proliferating cells are homogeneously distributed along the RMS, whereas in KOs they are located close to the ventricle (LV). The coronal section of control $(E, G)$ and $\operatorname{Vax} 1(F, H)$ mutant telencephala at $E 15.5$, analyzed by immunohistochemistry for ER81 $(E, F)$ and ISL1/2 $(G, H)$. CX, Cortex; $c p$, choroid plexus. Scale bars: $A, B, 500 \mu \mathrm{m} ; C, D, 200 \mu \mathrm{m} ; E-H, 100 \mu \mathrm{m}$.

ER81 (Fig. 4A), whereas in Vax1 mutants, this area is dramatically expanded $(\sim 10$ times the expected size $)$, rich in ER81positive cells. Given the expansion of the SVZ at P0, we wanted to understand whether cells contained in the SVZ were still actively proliferating at this stage. KI-67 is a protein expressed by all proliferating cells and is absent in the $\mathrm{G}_{0}$ phase (Scholzen and Gerdes, 2000; Scholzen et al., 2002). As expected, cells actively proliferating (therefore KI-67 positive) are readily detected in the SVZ and in the RMS in a WT brain (Fig. 4C). In Vax1 mutants, there are also many cells actively proliferating, but the distribution of these proliferating cells is abnormal: they are mostly located in the
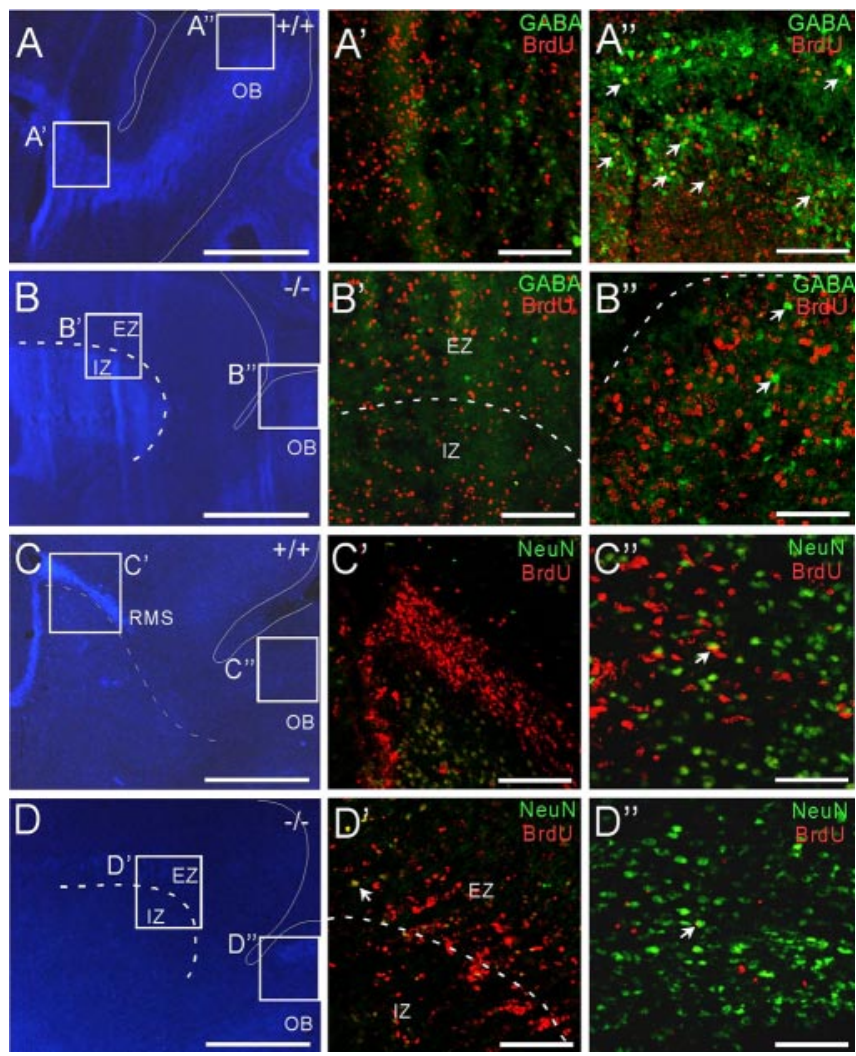

Figure 5. The expanded SVZ contains long-term survival precursor cells and continuous proliferation throughout embryogenesis and postnatal life. $A-A^{\prime \prime}$, Birthdating experiments in WT mice. A BrdU pulse was given at E14 and subsequently revealed at $P 0$ by immunohistochemistry in the SVZ ( $A^{\prime}$ ) or in the $O B\left(A^{\prime \prime}\right)$, together with an anti-GABA antibody (green). $B-B^{\prime \prime}$, Same as in $A-A^{\prime \prime}$, but experiments were performed in $\operatorname{Vax}^{-\prime-}$ mutants. $\left(-C^{\prime \prime}, A\right.$ BrdU pulse was given at $P 14$ in WT mice and subsequently revealed by immunohistochemistry at $P 19$ in the SVZ $\left(C^{\prime}\right)$ or in the $\mathrm{OB}\left(C^{\prime \prime}\right)$, together with an anti-neuronal nuclear marker (NeuN; green). $D-D^{\prime \prime}$, Same as in $C-C^{\prime \prime}$, but experiments were performed in Vax $1^{-1-}$ mutants. $A-D$, Low-power magnification of sagittal sections stained with DAPI showing the analyzed areas (squares) in WT $(A, C)$ and $\operatorname{Vax} 1^{-1-}(B, D)$ mice. IZ, Internal zone of the mutant SVZ; EZ, external zone of the mutant SVZ. EZ, External zone; IZ, internal zone. Scale bars: $A-D, 500 \mu \mathrm{m} ; A^{\prime}-D^{\prime \prime}, 200 \mu \mathrm{m}$.

periventricular area, and they are not protruding anteriorly toward the $\mathrm{OB}$ (Fig. $4 C, D$ ), perhaps suggesting that cells are aberrantly stalling in the deeper SVZ. The sections shown in Figure 4, $B$ and $D$, belong to the same brain and are adjacent to each other. By comparing these sections, it is evident that a large portion of the mutant-expanded SVZ (the anteriormost part; dashed line) is stained by ER81, but it is not positive for KI-67 and thus not proliferating. Therefore, the expanded SVZ at P0 contains a composite population of precursor pools, which ultimately is unable to properly give rise to the $\mathrm{OB}$ granule and periglomerular cells (Fig. 3) (see below). However, if we compare the image taken at P0 in Figure $4 B$ with that taken at P20 (Fig. 3B), we notice that during gestation some migration occurs, albeit inefficiently, from the SVZ to the OB (note some ER81-positive cells in the OB), whereas the absence of chain migration, indispensable at mature stages, makes migration from the SVZ to the OB impossible at these stages.

We wanted to understand whether this expanded SVZ contained long-term surviving cells or a continuously renewing population of precursors. We have performed BrdU birthdating experiments by injecting BrdU intraperitoneally in pregnant dams at E14, followed by anti-BrdU immunohistochemistry either at P0 (Fig. $5 A, B^{\prime \prime}$ ) or at P14 (supplemental Fig. 1, available at 
www.jneurosci.org as supplemental material). Our results indicate that indeed a large fraction of cells proliferating at E14 is still present at P0 (Fig. 5 $B^{\prime}$ ) and also at P14 (supplemental Fig. 1, available at www.jneurosci.org as supplemental material) and that although many cells born at E14 express the neurotransmitter GABA in the WT OB (Fig. 5A", arrows), very few cells born at this stage are expressing GABA in the mutant OB (Fig. $5 B^{\prime \prime}$ ), indicating, as expected, a failure in the correct differentiation of these precursors. However, not all of the cells born at E14 are likely to be still present in the P0 SVZ. In fact, if we compare $A^{\prime}$ with $B^{\prime}$ in Figure 5, we notice a decrease in BrdU+ cells in the Vax $1^{-/-}$mutants. A semiquantitative count of mitotic cells in a surface of $1600 \mu \mathrm{m}^{2}$ indicates a decrease in BrdU + cells of $~ 35 \%$ in knock-out $(\mathrm{KO})$ mice. This result is in agreement with the increased cell death that we have detected in the mutant SVZ (Fig. $2 E, F)$. Similar results were obtained by testing survival from P14 to P19 (Fig. 5C,D).

In summary, in vivo, we attribute the formation of the expanded SVZ to a continuous proliferation, both during embryogenesis and postnatal life, of precursor cells capable of long-term survival that accumulate in the SVZ, failing to migrate to the OB and to differentiate.

\section{Neurosphere cultures show hyperproliferation in $\operatorname{Vax1}^{-/-}$ NSCs derived at E15.5 but not in those derived at P0}

The postnatal SVZ is one of the reservoirs of the important population of neural stem cells, which can be selectively cultured in vitro as neurospheres under specific serum-free conditions in the presence of growth factors such as EGF and FGF2 (Reynolds and Weiss, 1992; Gritti et al., 1999; Galli et al., 2002). These culture conditions represent a stringent method by which only the stem cell component of a given neural cell population is progressively enriched (Gritti et al., 1999; Galli et al., 2002). To better characterize the biological properties of the precursor cells present in the SVZ expanded zone of the Vax1 mutant brain, we have established long-term growing NSC cultures from the LGE of $\operatorname{Vax} 1^{-/-}$ and WT littermates at E15.5 and at P0, approximately at the same developmental stages at which the in vivo analysis was performed (Fig. 4). As shown in Figure 6A, the growth rate of NSCs, isolated from the LGE at E15.5 (i.e., when in vivo we observe the Er81 expansion), is strongly affected by the absence of Vax1. In fact, $\mathrm{Vax}^{-/-}$cells proliferate at an amazing rate, about two logarithmic orders of magnitude above the WT counterpart.

The situation was instead quite different when we cultured NSCs from the P0 SVZ (Fig. 6B). In this case, the proliferation rate of mutant and WT NSCs becomes comparable. At P0, in vivo, we also observe comparable levels of proliferation between wild types and KOs (Fig. 4C,D), although mitotically active cells are differentially distributed within the SVZ, being concentrated only in the deeper layers of the SVZ of the mutant brain. This suggests that the action of Vax1 on SVZ precursor cell proliferation occurs essentially at embryonic stages and that it has profound repercussions on postnatal SVZ organization.

We used the in vitro culture system to understand the nature of the hyperproliferation defect observed in $\operatorname{Vax} 1^{-/-}$cells. Three mechanisms could be responsible for the alteration of the longterm growth rate observed: (1) differential cell survival; (2) a modification of the speed of progression through the cell cycle; or (3) an alteration of the frequency of symmetric (generation of two stem cells) versus asymmetric (generation of one stem cell and one more differentiated precursor cell, incapable of longterm survival) divisions of precursor cells. We started by assessing cell viability by MTT assay (see Materials and Methods), and we
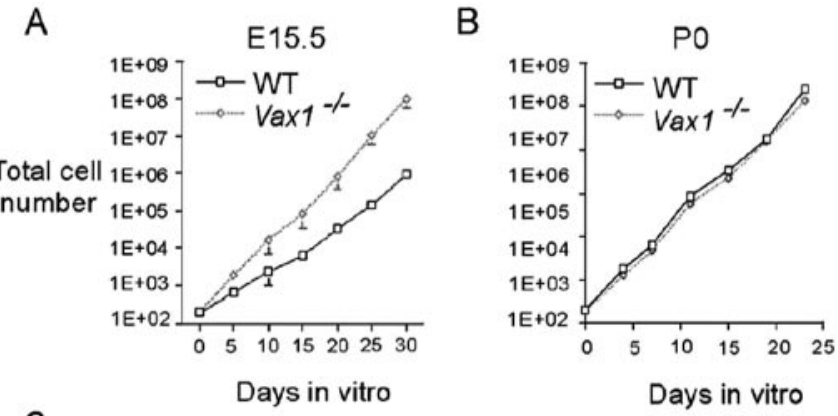

C

\begin{tabular}{|c|c|c|c|c|c|c|}
\hline $\begin{array}{c}\text { MITOTIC } \\
\text { FRACTION } \\
(\%)\end{array}$ & $6 \mathrm{hrs}$ & $24 \mathrm{hrs}$ & $30 \mathrm{hrs}$ & $54 \mathrm{hrs}$ & $\begin{array}{c}\text { CELL CYCLE } \\
\text { LENGTH } \\
\text { (hrs) }\end{array}$ & \\
\hline WT E15.5 & $33 \pm 1.6$ & $69 \pm 2.3$ & $74 \pm 3.4$ & $95 \pm 4.9$ & WT E15.5 & 80.0 \\
\hline Vax1\% E15.5 & $35 \pm 0.6$ & $82 \pm 3.5^{\star}$ & $91 \pm 5.2^{*}$ & $100 \pm 3.3$ & Vax $1 \%$ E15.5 & 77.5 \\
\hline
\end{tabular}

D

\begin{tabular}{|c|c|c|c|c|c|}
\hline $\begin{array}{c}\text { SURVIVAL } \\
\text { (assorbance at } \\
550 \mathrm{~nm} \text { ) }\end{array}$ & 0 hrs & $6 \mathrm{hrs}$ & $24 \mathrm{hrs}$ & $30 \mathrm{hrs}$ & $54 \mathrm{hrs}$ \\
\hline WT E15.5 & $0.144 \pm 0.005$ & $0.109 \pm 0.003$ & $0.315 \pm 0.005$ & $0.353 \pm 0.001$ & $0.454 \pm 0.002$ \\
\hline Vax1\%E15.5 & $0.127 \pm 0.006$ & $0.120 \pm 0.007$ & $0.308 \pm 0.004$ & $0.373 \pm 0.009$ & $0.477 \pm 0.005$ \\
\hline
\end{tabular}

Figure 6. Vax1 controls the proliferation of NSCs in vitro. $A, B$, Graphs indicate the growth rate of cultured NSCs isolated from the LGE of $\operatorname{Vax}^{-1-}$ and WT mice atE15.5 $(A)$ and P0 $(B)$. At E15.5, in the absence of Vax1, the proliferation rate is increased of approximately two logarithmic orders of magnitude when compared with cells obtained from WT mice. At PO $(B)$, we could not detect any difference in proliferation between WT and $\mathrm{Vax}^{-1-}$ cells. The total cell number is indicated on the $y$-axis, and days in culture are indicated on the $x$-axis. C, The table shows the mitotic fractions of WT and Vax $1^{-1-}$ NSCs, isolated from E15.5 LGE, obtained through BrdU incorporation. Note statistically significant differences at 24 and $30 \mathrm{hr}$ after plating, with Vax $1^{-1-}$ cells displaying a higher rate of proliferation compared with WT NSCs (Student's $t$ test; ${ }^{*} p<0.005$ ). By cumulative BrdU labeling, no difference in the overall cell cycle length could be observed between WT and Vax $1^{-1-}$ NSCS. D, No effect of Vax 1 deletion on cell viability could be detected after 6, 24, 30, and $54 \mathrm{hr}$ after plating, as determined by MTT assay. Values are expressed as absorbance at $550 \mathrm{~nm}$.

determined that there were no differences between the survival capabilities of long-term stem cell cultures in the presence or absence of a functional $\operatorname{Vax} 1$ gene product at any time point (Fig. $6 D)$. Therefore, to verify whether Vaxl deletion might involve cell cycle alterations, we performed cumulative BrdU-labeling experiments and estimated the duration of the cell cycle $\left(T_{c}\right)$ of both WT and $\operatorname{Vaxl}^{-/-}$cells. As shown in Figure $6 \mathrm{C}$, both WT and mutant cells displayed a similar cell cycle time: $T_{\mathrm{c}}=80.0$ for WT and $T_{\mathrm{c}}=77.5$ for $\operatorname{Vax1}^{-/-}$cells $(n=3)$. Of note, $\operatorname{Vaxl}^{-1-}$ NSCs displayed a higher rate of proliferation when compared with WT NSCs, as determined by the analysis of the mitotic fractions at 24 and $30 \mathrm{hr}$ after plating (Fig. 6C), thus suggesting that a greater fraction of cells in the $\operatorname{Vax} 1^{-/-}$NSC cultures were actively dividing when compared with WT cultures. Given these observations, we have to conclude that the increased total number of $\operatorname{Vax}^{-1-}$ cells in culture, in the absence of altered cell cycle length and survival capabilities together with the presence of increased mitotic fractions, indicates that the absence of $\operatorname{Vax} 1$ enhances stem cell generation through increased numbers of symmetric divisions at the expense of asymmetric divisions. Interestingly, this finding is also reported for $E m x 2$, a homeobox gene highly related to $\operatorname{Vax1}$ (Galli et al., 2002).

\section{The differentiation of precursor cells from the SVZ is compromised}

We then wanted to understand how differentiation occurs in vivo in the derivatives of the SVZ. Given the lack of specific markers for each cell type present in the SVZ, currently the most accurate 

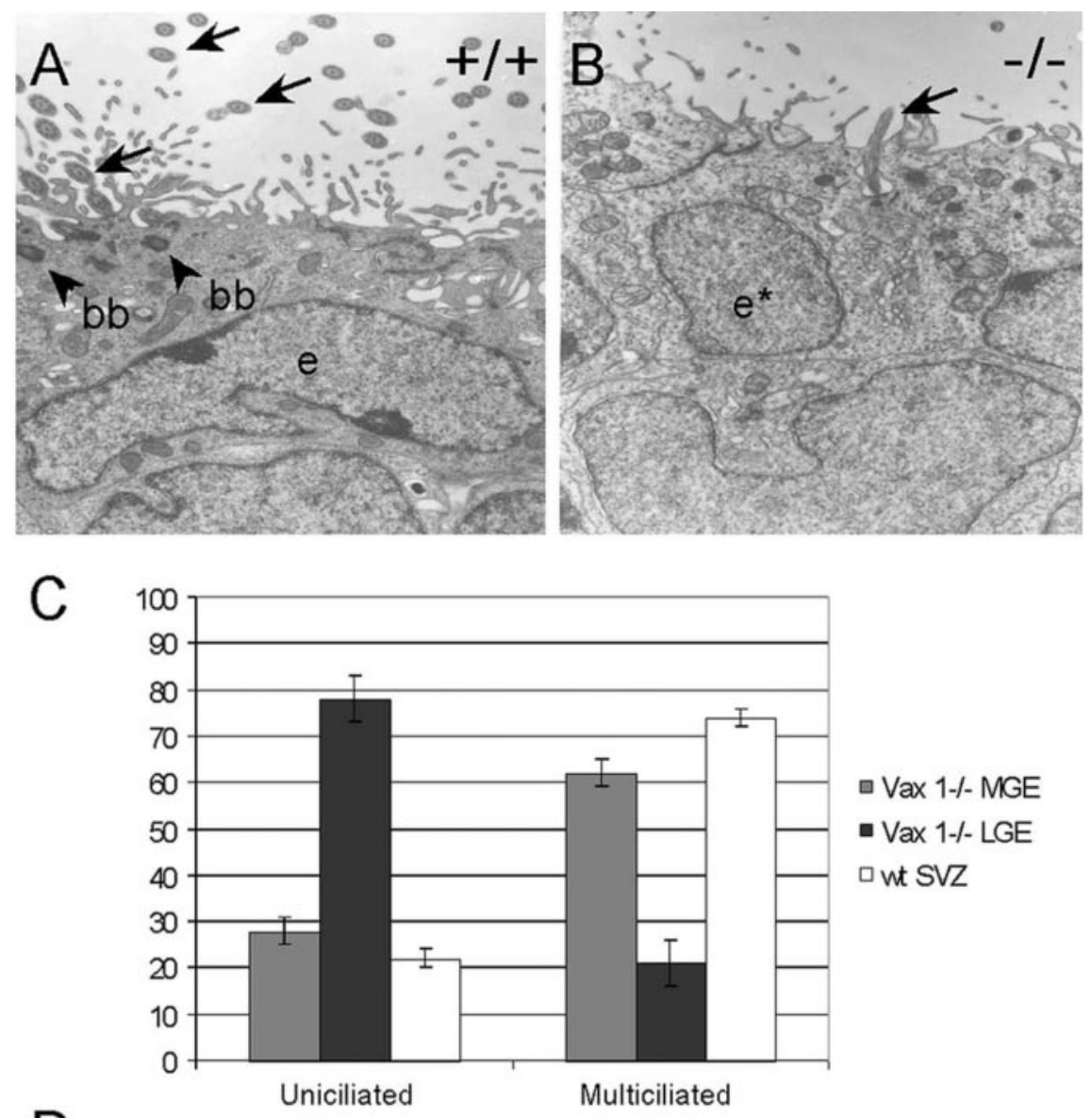

D
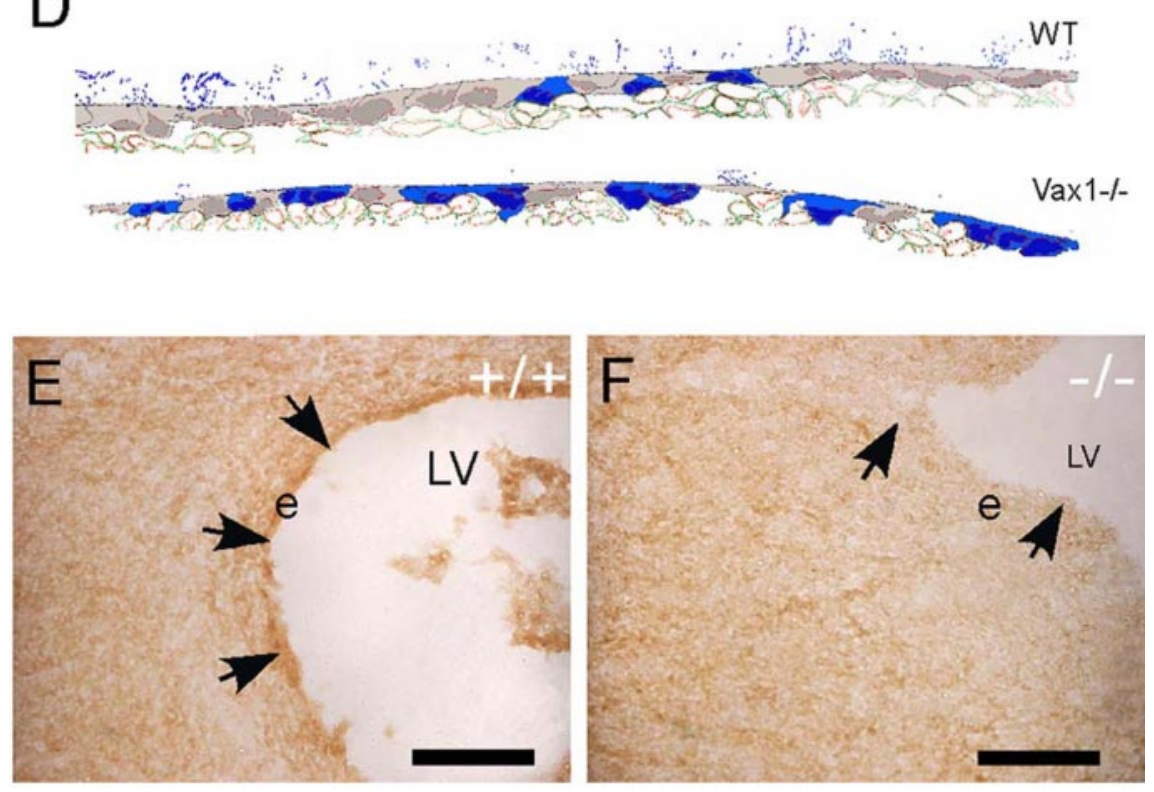

Figure 7. In the absence of Vax 1 , the SVZ contains undifferentiated ependymal cells. $A, B$, Electron microscopy images of ependymal cells of P20 wild types $(A)$ and KOS $(B)$. In the absence of Vax1, ependymal cells appear undifferentiated with an unusual morphology, light cytoplasms, and a reduced number of cilia (arrows indicate cilia; arrowheads indicate basal bodies). C, Quantification of multiciliated ependymal cells in the MGE and LGE of PO Vax $1^{-1-}$ brains and in the SVZ of WT controls. Note the strong reduction of multiciliated ependymal cells in the LGE of Vax 1 mutant mice (the anlage of the mature SVZ) and the unvaried number of mature (uniciliated) ependyma in the mutant MGE. D, Reconstruction of a representative tract of the SVZ, highlighting the position and the characteristics of ependymal cells (gray; in case of a differentiated morphology; blue, in case of an immature morphology). Red lines indicate the nuclear membranes, and green lines indicate the cellular membranes. $E, F$, Immunohistochemistry for Noggin on coronal sections obtained from P15 WT $(E)$ and $\operatorname{Vax}^{-/-}(F)$ telencephala. Note the expression of Noggin in the ependyma (e; indicated by the arrows) of WT brains and the low levels (practically absent) of Noggin in Vax1 mutants. bb, Basal bodies; e, ependymal cell; LV, lateral ventricle. Scale bars, $100 \mu \mathrm{m}$. method for the identification of the different cell types is the ultrastructural analysis. We analyzed the ependymal population of cells. Ependyma constitute the first layer of cells surrounding the ventricle. They are multiciliated (Fig. 7A, arrows), with multiple basal bodies (arrowheads) and a scarce endoplasmic reticulum. As can be observed in Figure $7 B$, in the absence of Vaxl, the majority of cells (e) in the ventricular layer associated with the expanded zone are not multiciliated. Instead, they present a single cilium, an abundant endoplasmic reticulum, and a centriole perpendicular to the basal body (Tramontin et al., 2003). This is typical of highly undifferentiated ependyma. We have quantified this defect by counting the number of ependymal cells in the WT SVZ and in the mutant medial ganglionic eminence (MGE) and LGE. Because of a delay in development, it is still possible to distinguish between the MGE and LGE, a fact that is not possible in wild type. As shown in Figure 7C, whereas in the WT SVZ most of the ependymal cells are fully differentiated and therefore present many cilia, in the mutant LGE the ventricular zone is instead highly deprived of multiciliated cells. Interestingly, the converse experiment of quantifying the number of uniciliated cells gave complementary results, working as an internal control for our results. To help visualize the phenomenon and to summarize the data, we have drawn a reconstruction of the mutant and WT SVZ (Fig. 7D), in which blue cells represent uniciliated cells. Note the great reduction of mature ependyma in the mutant SVZ.

Ependyma play an important role in SVZ function and organization. In fact, ependyma secrete Noggin, a potent antagonist of morphogens of the bone morphogenetic protein family, which is crucial in this context for maintaining a defined neurogenic niche in the adult brain (Lim et al., 2000). Because of the reduction in ependymal cell differentiation, we hypothesized a possible defect in Noggin secretion within the SVZ. As expected, we have observed the complete absence of Noggin in the SVZ at P20 (Fig. 7E,F). Lack of Noggin is the likely cause of aberrant differentiation within the SVZ.

We then studied the expression of GFAP, a well accepted marker for the astrocytic population of cells. In the RMS, neuroblasts (A-cells) migrate wrapped in gliotubes, formed by GFAP-positive cells. As shown in Figure 8A, in P20 WT brains, GFAP immunohistochemistry reveals an abundant presence of astrocytes in the SVZ. Within the RMS, GFAP labels cells 


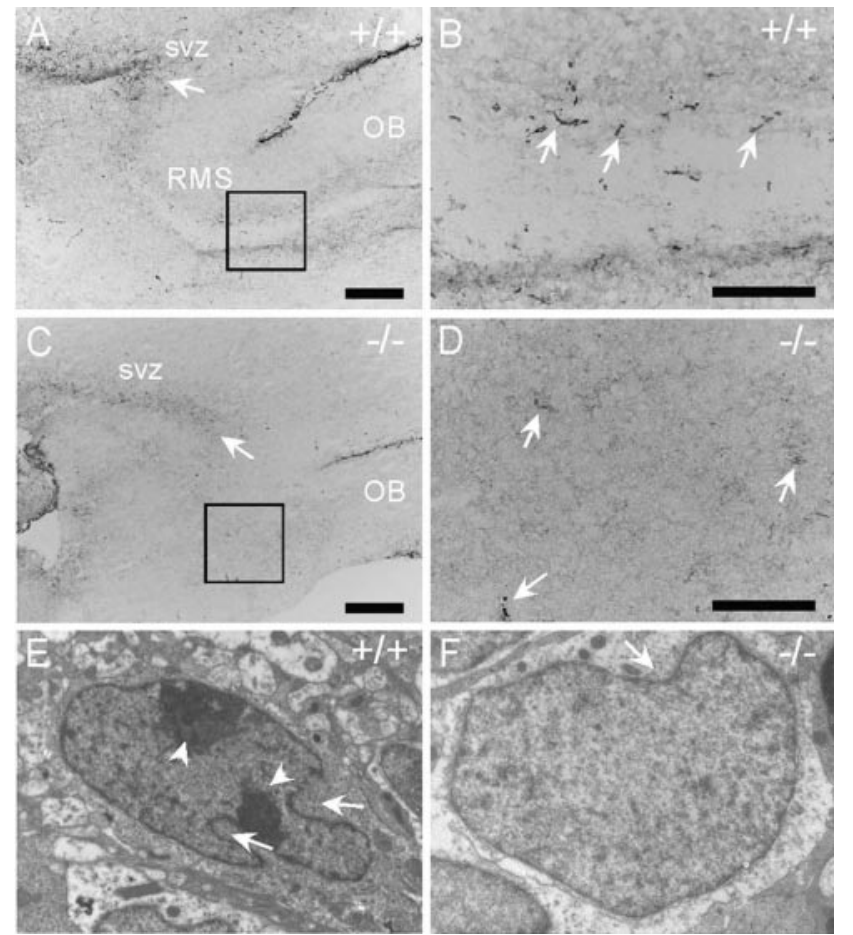

Figure 8. In the $\mathrm{Vax} 1^{-1-} \mathrm{SVZ}$, astrocytes are absent or mostly immature. $A-D$, Immunohistochemistry using an anti-GFAP antibody, which labels astrocytes in the SVZ and in the RMS (arrows) of P15 WT $(A, B)$ and $\operatorname{Vax}^{-1-}(C, D)$ animals. In the absence of Vax1, astrocytes are detected in the SVZa and in the outermost area of the expanded zone ( $C$; arrow). However, astrocytes are either absent or mainly disorganized in the RMS ( $D$; arrows). E, $F$, EM images showing representative astrocytes from WT $(E)$ and $\operatorname{Vax} 1(F)$ mutants. The arrowheads in $E$ point to the readily detectable nucleoli, whereas the arrows indicate the evident circumvolutions of the nuclear membrane, typical hallmarks of mature astrocytes. Both of these features are absent or extremely reduced in the few astrocytes present in the Vax 1 mutants $(F)$. Scale bars: $A, C, 500 \mu \mathrm{m} ; B, D, 100 \mu \mathrm{m}$.

located at its borders, and the center of the RMS is unstained for GFAP because it contains mainly the GFAP-negative A- and C-cells. If we compare this situation with that displayed by the Vax1 mutants (Fig. 8C,D), we notice a significant reduction of GFAP expression in the SVZ, because of the poor differentiation of the astrocytes present in this area. In fact, in the RMS the presence of GFAP-positive cells is severely compromised or completely absent (Fig. $8 D$ ). At the ultrastructural level, mature astrocytes are characterized by marked nuclear convolutions (Fig. $8 E$, arrows) and by the presence of distinct nucleoli (arrowhead) (Doetsch et al., 1997). None of these features are present in the mutant astrocytes, which instead display round nuclei, devoid of nucleoli (Fig. $8 F$ ). We also calculated the area/perimeter ratio for astrocytes in WT and mutant astrocytes: Vax1 KO mice present higher ratios (0.88) than WT mice (0.51).

\section{Migration from the SVZ is severely compromised in $\operatorname{Vax1}^{-/-}$mice}

The hypoplastic OBs of the Vax1 mutants, the absence (or severe reduction) of the RMS, the expansion of the SVZ, and the impaired differentiation of the several cell types within the SVZ/ RMS point to a possible migration defect from the SVZ toward the OB. This fact is also supported by abnormal ultrastructural data. As shown in Figure 9, $A$ and $B$, the round-shaped migrating neuroblasts are surrounded by many abundant intercellular spaces (arrows in $A$ ), which have been proposed to be a sign of cellular migration (Jankovski and Sotelo, 1996; Doetsch et al.,
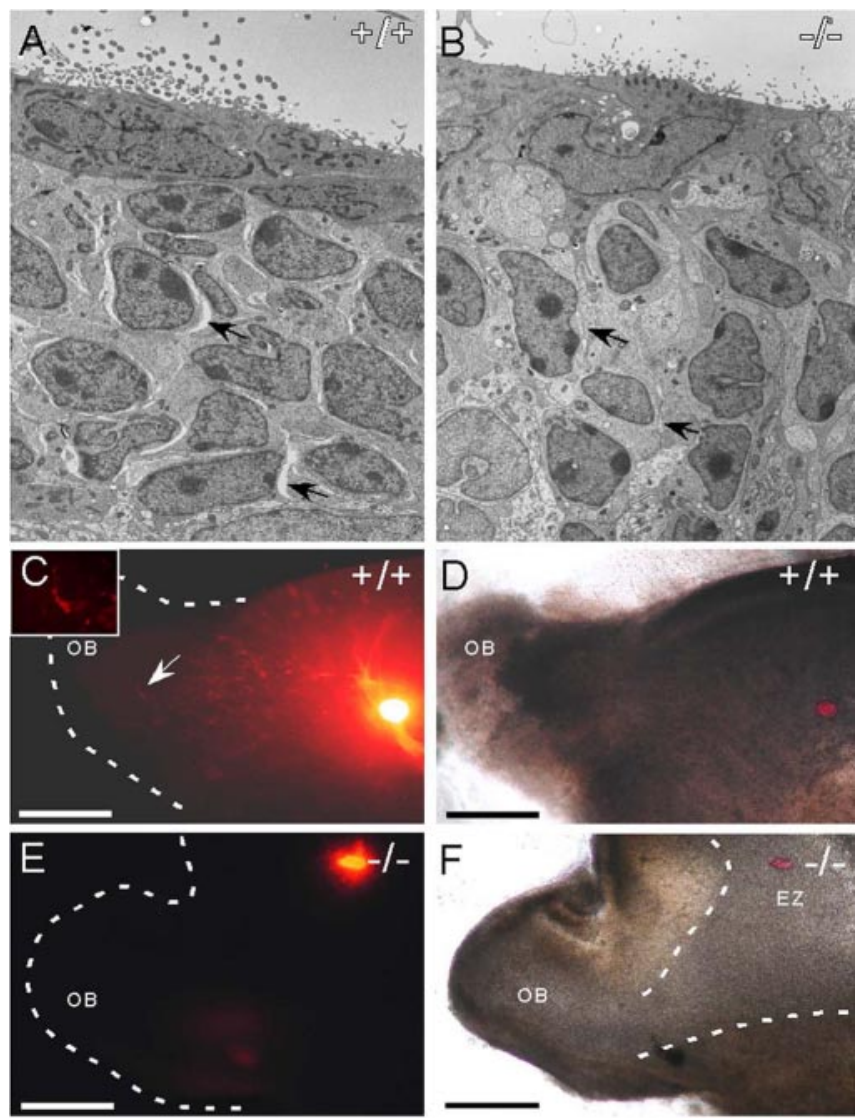

Figure 9. $\ln \operatorname{Vax}^{-1-}$ mutants, neuroblasts fail to migrate to the $\mathrm{OB} . A, B, \mathrm{SVZ}$ of WT and mutant $\mathrm{Vax}^{-/-}$mice at $\mathrm{PO}$ analyzed by transmission electron microscopy. Although in wild type the SVZ contains many migrating neuroblasts, separated by clear intercellular spaces (arrows), the mutant SVZ does not present any anatomical evidence of migration. $C-F$, Cell migration tracing by Dil injection. In PO WT brain $(C, D)$, Dil-labeled cells in the SVZ can migrate to the $O B$ after $48 \mathrm{hr}$ in culture. The inset in $C$ shows a migrating Dil-labeled cell in the $O B$ with an elongated cell body a long leading process. No sign of migration was detected in mutant mice when a Dil crystal was placed in the internal expanded zone $(E Z)(E, F) . D, F$, Bright-field images of $C$ and $E$. Scale bars: $C-F, 500 \mu \mathrm{m}$.

1997). If we compare $A$ with $B$ in Figure 9, we notice that in Vax1 mutant brains the intercellular spaces are absent, suggesting a possible migration defect of the A-cells.

To obtain a functional proof of this, we performed organotypic slice cultures (Fig. 9C-F) and Matrigel cultures (supplemental Fig. 2, available at www.jneurosci.org as supplemental material) from P0 WT and $\operatorname{Vax} 1^{-1-}$ brains sectioned in a sagittal orientation. We then implanted an acrylic bead soaked in DiI in the SVZ of both WT and Vax1 mutant slices and let the culture develop for $48 \mathrm{hr}$. As a result (Fig. 9C-F), it became readily clear that cells located in the deep SVZ of WT slices can migrate at a very fast rate; for example, the cell indicated by the arrow (Fig. $9 C$ ), shown at a higher magnification in the inset, displays the typical migrating morphology with a clear leading edge and has traveled over a distance of $1 \mathrm{~mm}$ in $48 \mathrm{hr}$. On the contrary, if we observe the Vax1 mutant slices (Fig. 9E), not a single cell is capable of migrating away from the SVZ.

\section{The defect of migration from the SVZ is mostly of a cell nonautonomous nature}

To understand whether altered differentiation of the RMS prevents the migration of precursor cells from the SVZ to the OB, we performed transplant experiments $(n=12)$. We have crossbred 

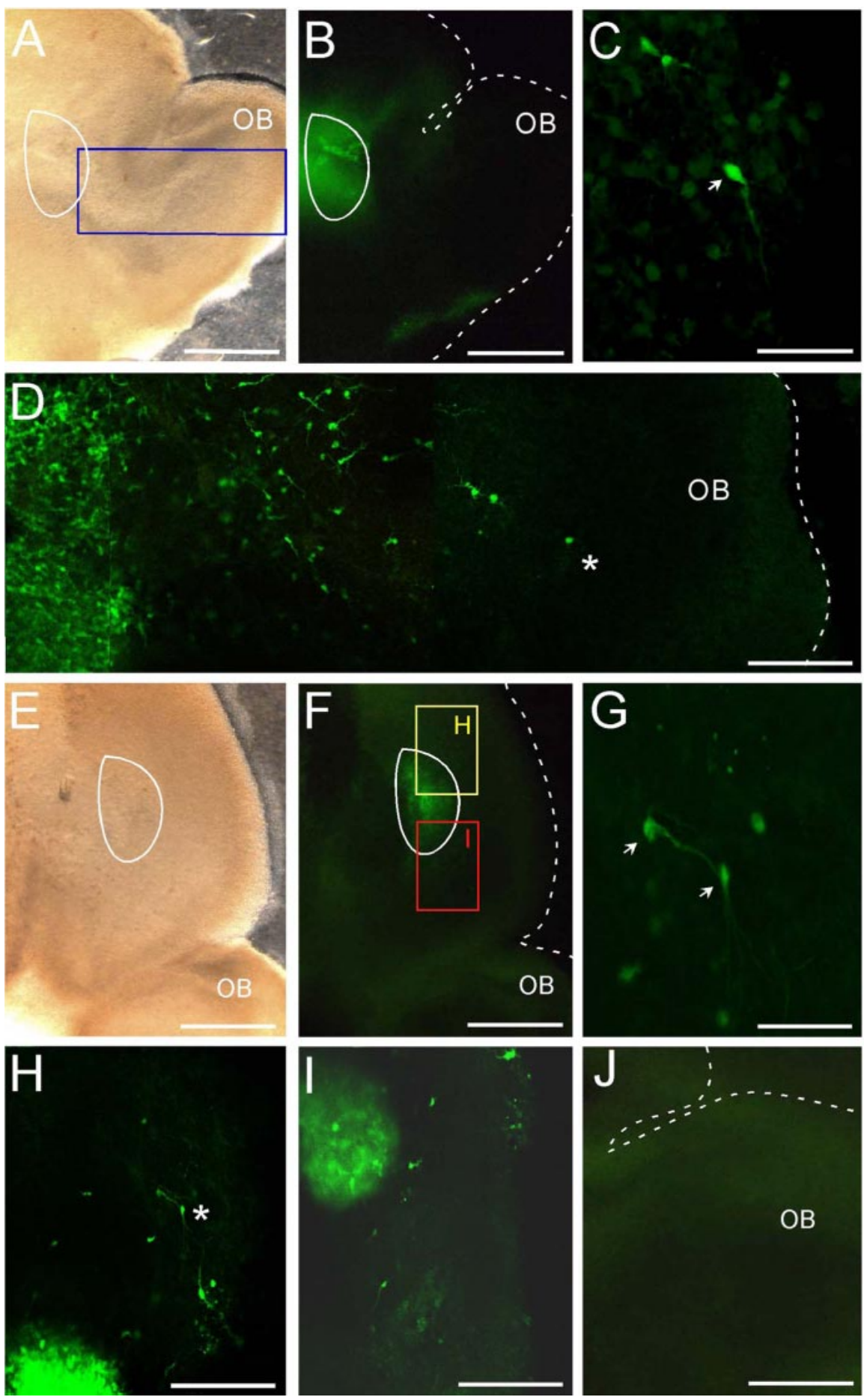

Figure 10. Transplant experiments suggest a cell nonautonomous defect in Vax1 mutants. A, B, Low-magnification photographs showing the transplanted internal expanded zone (solid white line) from GFP-Vax ${ }^{-/-}$mice into a PO WT organotypic slice culture. C, D, GFP-positive cells migrating from the transplanted internal expanded zone ( $A$; blue square) and entering the $0 B$ after $3 \mathrm{~d}$ in culture. $C$, High-magnification of GFP-positive migrating neuroblasts in the $O B$ ( $D$; asterisk) with elongated cell bodies and a long leading process. E, F, Low-magnification micrographs showing the transplanted SVZ from GFP-WT mice into a PO Vax $1^{-/-}$organotypic slice culture, showing few migrating cells from the explants. G-I, High-magnification of GFP-positive cells migrating from the transplanted SVZ. Labeled cells with elongated cell bodies and evident leading processes migrate in different directions $(H, I)$, but no cells from the transplanted SVZ were found in the OB after $3 \mathrm{~d}$ in culture (J). Scale bars: $A, B, E, F, 200 \mu \mathrm{m}$; $C, G, 500 \mu \mathrm{m} ; D, H-J, 100 \mu \mathrm{m}$

$\operatorname{Vax1}^{+/-}$mice with $\beta$-actin-GFP transgenic mice (Okabe et al., 1997) to label all of the SVZ cells. We were therefore able to transplant a P0 Vax1 ${ }^{-/-}$GFP-positive SVZ into an organotypic slice culture of a WT P0 brain (Fig. $10 A-D$ ). After culturing the slice for $40 \mathrm{hr}$, we could detect a large number of GFP-positive cells directed toward the OB. Although the migration does not resemble the tight chain migration typical of the RMS, the general direction and the rate of migration seems appropriate $(400 \mu \mathrm{m} / 36 \mathrm{hr})$, indicating that within the mutant SVZ there are cells capable of migration, if placed in the correct environment. This would argue for a cell nonautonomous nature of the defect. We also performed the converse experiment (Fig. $10 E-J)$ by transplanting WT GFP-positive SVZ cells into a P0 Vax1 KO organotypic slice. As can be observed, in this case, the rate of migration is greatly reduced (Fig. 10 , compare $H, I$ with $D$ ) in number, distance traveled (maximum, 150-200 $\mu \mathrm{m} / 36 \mathrm{hr}$ ), and direction (very few cells take a ventroanterior pathway, where the RMS would be formed). These results suggest that although the SVZ contains a diversified population of cells in different proliferative and differentiative states, the lack of correct differentiation of the cell types that compose the RMS and the consequent organization of the RMS itself is greatly compromising the postnatal migration from the SVZ to the OB, severely impairing the $\mathrm{OB}$ interneuron turnover.

\section{Discussion}

Vax1 is expressed in the neurogenic areas of the postnatal brain

Vax genes have been proven fundamental transcription factors for eye development (Bertuzzi et al., 1999; Hallonet et al., 1999; Ohsaki et al., 1999; Schulte et al., 1999; Barbieri et al., 2002; Take-uchi et al., 2003). More recently, Vaxl was shown to play an important role in subcortical telencephalon development (Hallonet et al., 1999; Taglialatela et al., 2004); however, the expression and the possible function of Vaxl in the postnatal brain was never addressed before. Here we studied the expression and the function of Vaxl in the SVZ at postnatal stages, when the SVZ and the RMS have completed their developmental stages, focusing mainly on a P20 stage. We have detected, by in situ hybridization, expression of Vaxl in the telencephalic SVZ and in the hippocampus, areas where adult neurogenesis occurs in the adult brain.

\section{Vax1 loss of function is associated with precursor cell proliferation and differentiation}

Our recent study (Taglialatela et al., 2004) has shown that during embryonic development, Vax1 is expressed in the subcortical telencephalon by proliferating cells at different levels and that its expression is sharply downregulated after cellular differentiation; moreover, 
KI-67 immunohistochemistry shows an expansion of proliferating precursors in the embryonic SVZ (Taglialatela et al., 2004).

Interestingly, the new findings presented here indicate that Vaxl expression is also maintained in the postnatal brain, specifically in those scarce pools of proliferating precursor cells (Weissman et al., 2001), strengthening the hypothesis that this putative transcriptional regulator is essential for neural precursor cell proliferation and differentiation.

One of the most striking observations in the telencephalon of $\operatorname{Vax} 1^{-/-}$mice is the progressive formation of a greatly enlarged SVZ. By performing in vivo birthdating experiments (Fig. 5), we show that precursor cells are continuously proliferating both embryonically and postnatally and that they are capable of longterm survival, failing to differentiate correctly. This leads to the formation of the expanded SVZ, densely packed, where apoptosis eventually occurs (Fig. 2 E,F). To better understand the nature of this defect, we cultured stem cells in a defined medium that allows the enrichment and the expansion of NSCs at the expense of the transit amplifying population of precursor cells (Gritti et al., 1999; Galli et al., 2002). Cultured NSCs derived from the LGE of Vax1 mutant mice at E15.5 display a dramatically increased rate of proliferation, $\sim 100$ times higher than the WT controls (Fig. 6). In a cultured stem cell pool, the rate of cell expansion is the result of cell cycle length, cell death, and the ratio between symmetric and asymmetric divisions. We have analyzed these three parameters in our culture system and found that, indeed, in the absence of $\operatorname{Vax} 1$, there is an increased mitotic fraction of cells in the absence of cell death and cell cycle length alterations. Our interpretation is therefore that $\operatorname{Vax} 1$ acts as a potent negative regulator of stem cell proliferation. In the absence of this transcription factor, symmetric divisions are favored, increasing significantly the stem cell pool at the expense of asymmetric divisions, and therefore generating fewer differentiated progenitors.

When we cultured NSCs from P0 instead of E15.5, we obtained proliferation rates that were comparable between wild types and KOs. This result indicates that $\operatorname{Vax} 1$ acts primarily as a controller of NSC proliferation at early stages and could be in agreement with the situation found in vivo, in which we observed excessive proliferation of precursor cells (Taglialatela et al., 2004), but at P0 the number of KI-67-positive cells in wild types and KOs seems to diverge in positioning rather than in number. If this is the case, we could conclude that Vaxl acts as a controller of early stages of SVZ development but that its effects have severe repercussions over the organization of the postnatal SVZ and RMS. It is worth remembering that the lineage relationship between embryonic and postnatal NSCs is not yet clear. For example, multipotent NSCs isolated from the postnatal but not the embryonic SVZ express GFAP, and NSCs exhibit heterogeneous expression of intermediate filaments during development (Imura et al., 2003), leaving the possibility of a time-dependent role of transcriptional regulators in the NSC lineage.

Emx2 is a homeobox gene related to $\operatorname{Vax} 1$. It has also been correlated with an alteration in the type of cell divisions necessary for the self-maintenance of the stem cell compartment in vitro (Galli et al., 2002). If this gene is deleted, NSC proliferation, analyzed from cultures obtained from the P0 SVZ, is increased, although not as dramatically as $\operatorname{Vax} 1$ at E15.5. Therefore, it seems that although Vax1 and Emx2 have the same effect in vitro, their timing of action could be different. It would be interesting to know what happens to the Emx2 mutant SVZ in vivo, although it could be difficult to make precise comparisons at postnatal stages, given the fact that the Emx2 mutants die at birth (Pellegrini et al., 1996; Yoshida et al., 1997).
Of particular interest to us is the fact that in the derivatives of the LGE we observe a dramatic expansion of the ER81 population of precursor cells at mid-embryogenesis (Fig. 4). ER81 is associated with cellular proliferation, and in particular it was found overexpressed in several breast cancer cell lines. Moreover, it is a target of the transmembrane receptor kinase Her2/Neu (de Launoit et al., 2000; Bosc et al., 2001; Bosc and Janknecht, 2002; Goel and Janknecht, 2004) and can activate SMAD7, an inhibitor of the TGF- $\beta$ pathway, which is often affected in several forms of cancer and cellular hyperproliferation (Dowdy et al., 2003). Therefore, the expanded expression of ER81, in conjunction with precursor cell expansion in the SVZ, seems to be particularly interesting and may highlight a function of VAX1 in the repression of ER81 and possibly a role for Vax genes in tumorigenesis.

\section{The organization of the SVZ and RMS is impaired in $\operatorname{Vax}^{-1-}$ mice}

In the presence of an increased mass of ER81-positive precursors, it would be intuitive to expect more cells migrating to the $\mathrm{OB}$, because these precursor cells are normally destined to become granule and periglomerular cells. Instead, $\operatorname{Vax1^{-1-}} \mathrm{OB}$ are severely hypoplastic (Fig. 3). All of the data presented here favor the hypothesis that $\mathrm{OB}$ hypoplasia is a consequence of the lack of precursor cell migration from the expanded SVZ to the OB (Fig. 8 ), although some migration occurs from the peripheral areas of the expanded zone (Fig. $8 H$ ). This fact raised the question whether the defect observed in Vax1 mutants is of a cell autonomous or cell nonautonomous nature. To directly address this issue, we have performed grafting experiments in organotypic slice cultures. When we transplant $\operatorname{Vaxl}^{-1-} ; G F P^{+/-}$cells into a P0 WT SVZ, within 36-72 hr we observe a significant stream of migrating neuroblasts directed toward the OB. This indicates that mutant cells from the donor SVZ are capable of migration in a WT environment, therefore suggesting a defect of a cell nonautonomous nature. We also performed the converse experiment, in which WT SVZ cells were transplanted into a P0 SVZ, showing that migration is not only greatly reduced but also disorganized and not specifically directed toward the OB. The transplant experiments support the anatomical and molecular analysis, both at a cellular and ultracellular level (Figs. 6-8), and point toward a major role for $\operatorname{Vax} 1$ in the organization of the postnatal SVZ and RMS.

Our current working hypothesis on the function of Vax1 in SVZ proliferation and differentiation is that Vaxl acts as a negative regulator of stem cell proliferation, mainly at midembryogenesis. In the absence of this protein, the increased number of symmetric divisions of stem cells occurs at the expense of more differentiated progenitors, impairing the timely assembly of the neurogenic niche, therefore affecting postnatal neurogenesis and tangential migration. Because our transplant experiments show that $\operatorname{Vax}^{-/-}$cells are capable of migration toward the OB in a correctly formed RMS, we raise the possibility that the migration defect is secondary to the aberrant proliferation and differentiation. In this respect, it will be highly interesting to study a Vax1-inducible mouse mutant that would allow embryonic development to occur correctly, ablating $\operatorname{Vax} 1$ function only postnatally in the SVZ.

\section{References}

Alcantara S, Ruiz M, D’Arcangelo G, Ezan F, de Lecea L, Curran T, Sotelo C, Soriano E (1998) Regional and cellular patterns of reelin mRNA expression in the forebrain of the developing and adult mouse. J Neurosci 18:7779-7799.

Altman J (1969) Autoradiographic and histological studies of postnatal 
neurogenesis. III. Dating the time of production and onset of differentiation of cerebellar microneurons in rats. J Comp Neurol 136:269-293.

Alvarez-Buylla A, Lim DA (2004) For the long run: maintaining germinal niches in the adult brain. Neuron 41:683-686.

Alvarez-Buylla A, Garcia-Verdugo JM, Tramontin AD (2001) A unified hypothesis on the lineage of neural stem cells. Nat Rev Neurosci 2:287-293.

Barbieri A, Broccoli V, Bovolenta P, Alfano G, Marchitiello A, Mocchetti C, Crippa L, Bulfone A, Marigo V, Ballabio A, BanfiS (2002) Vax2 inactivation in mouse determines alteration of the eye dorsal-ventral axis, misrouting the optic fibers and eye coloboma. Development 129:805-813.

Ben-Hur T, Rogister B, Murray K, Rougon G, Dubois-Dalcq M (1998) Growth and fate of PSA-NCAM+ precursors of the postnatal brain. J Neurosci 18:5777-5788.

Bertuzzi S, Hindges R, Mui SH, O’Leary DDM, Lemke G (1999) The homeodomain protein Vaxl is required for axon guidance and major tract formation in the developing forebrain. Genes Dev 13:3092-3105.

Bonfanti L, Theodosis DT (1994) Expression of polysialylated neural cell adhesion molecule by proliferating cells in the subependymal layer of the adult rat, in its rostral extension and in the olfactory bulb. Neuroscience 62:291-305.

Bosc DG, Janknecht R (2002) Regulation of Her2/neu promoter activity by the ETS transcription factor, ER81. J Cell Biochem 86:174-183.

Bosc DG, Goueli BS, Janknecht R (2001) HER2/Neu-mediated activation of the ETS transcription factor ER81 and its target gene MMP-1. Oncogene 20:6215-6224.

de Launoit Y, Chotteau-Lelievre A, Beaudoin C, Coutte L, Netzer S, Brenner C, Huvent I, Baert JL (2000) The PEA3 group of ETS-related transcription factors. Role in breast cancer metastasis. Adv Exp Med Biol 480:107-116.

Doetsch F (2003) The glial identity of neural stem cells. Nat Neurosci 6:1127-1134.

Doetsch F, Scharff C (2001) Challenges for brain repair: insights from adult neurogenesis in birds and mammals. Brain Behav Evol 58:306-322.

Doetsch F, Garcia-Verdugo JM, Alvarez-Buylla A (1997) Cellular composition and three-dimensional organization of the subventricular germinal zone in the adult mammalian brain. J Neurosci 17:5046-5061.

Doetsch F, Caille I, Lim DA, Garcia-Verdugo JM, Alvarez-Buylla A (1999) Subventricular zone astrocytes are neural stem cells in the adult mammalian brain. Cell 97:703-716.

Dowdy SC, Mariani A, Janknecht R (2003) HER2/Neu- and TAK1mediated up-regulation of the transforming growth factor beta inhibitor Smad7 via the ETS protein ER81. J Biol Chem 278:44377-44384.

Galli R, Fiocco R, De Filippis L, Muzio L, Gritti A, Mercurio S, Broccoli V, Pellegrini M, Mallamaci A, Vescovi AL (2002) Emx2 regulates the proliferation of stem cells of the adult mammalian central nervous system. Development 129:1633-1644.

Garcia-Verdugo JM, Doetsch F, Wichterle H, Lim DA, Alvarez-Buylla A (1998) Architecture and cell types of the adult subventricular zone: in search of the stem cells. J Neurobiol 36:234-248.

Goel A, Janknecht R (2004) Concerted activation of ETS protein ER81 by p160 coactivators, the acetyltransferase p300 and the receptor tyrosine kinase HER2/Neu. J Biol Chem 279:14909-14916.

Gritti A, Frolichsthal-Schoeller P, Galli R, Parati EA, Cova L, Pagano SF, Bjornson CR, Vescovi AL (1999) Epidermal and fibroblast growth factors behave as mitogenic regulators for a single multipotent stem cell-like population from the subventricular region of the adult mouse forebrain. J Neurosci 19:3287-3297.

Hallonet M, Holleman T, Wehr R, Jenkins NA, Copeland NG, Pieler T, Gruss $\mathrm{P}$ (1998) Vaxl a novel homeobox-containing gene expressed in the developing anterior ventral forebrain. Development 125:2599-2610.

Hallonet M, Hollemann T, Pieler T, Gruss P (1999) Vax1, a novel homeobox-containing gene, directs development of the basal forebrain and visual system. Genes Dev 13:3106-3114.

Imura T, Kornblum HI, Sofroniew MV (2003) The predominant neural stem cell isolated from postnatal and adult forebrain but not early embryonic forebrain expresses GFAP. J Neurosci 23:2824-2832.

Jankovski A, Sotelo C (1996) Subventricular zone-olfactory bulb migratory pathway in the adult mouse: cellular composition and specificity as determined by heterochronic and heterotopic transplantation. J Comp Neurol 371:376-396.

Johansson CB, Momma S, Clarke DL, Risling M, Lendahl U, Frisen J (1999) Identification of a neural stem cell in the adult mammalian central nervous system. Cell 96:25-34.

Kornack DR, Rakic P (2001) The generation, migration, and differentiation of olfactory neurons in the adult primate brain. Proc Natl Acad Sci USA 98:4752-4757.

Law AK, Pencea V, Buck CR, Luskin MB (1999) Neurogenesis and neuronal migration in the neonatal rat forebrain anterior subventricular zone do not require GFAP-positive astrocytes. Dev Biol 216:622-634.

Lim DA, Tramontin AD, Trevejo JM, Herrera DG, Garcia-Verdugo JM, Alvarez-Buylla A (2000) Noggin antagonizes BMP signaling to create a niche for adult neurogenesis. Neuron 28:713-726.

Lois C, Garcia-Verdugo JM, Alvarez-Buylla A (1996) Chain migration of neuronal precursors. Science 271:978-981.

Long JE, Garel S, Depew MJ, Tobet S, Rubenstein JL (2003) DLX5 regulates development of peripheral and central components of the olfactory system. J Neurosci 23:568-578.

McLean JH, Shipley MT (1988) Postmitotic, postmigrational expression of tyrosine hydroxylase in olfactory bulb dopaminergic neurons. J Neurosci 8:3658-3669.

Miragall F, Kadmon G, Faissner A, Antonicek H, Schachner M (1990) Retention of J1/tenascin and the polysialylated form of the neural cell adhesion molecule (N-CAM) in the adult olfactory bulb. J Neurocytol 19:899-914.

Ohsaki K, Morimitsu T, Ishida Y, Kominami R, Takahashi N (1999) Expression of the Vax family homeobox genes suggests multiple roles in eye development. Genes Cells 4:267-276.

Okabe M, Ikawa M, Kominami K, Nakanishi T, Nishimune Y (1997) “Green mice" as a source of ubiquitous green cells. FEBS Lett 407:313-319.

Pellegrini M, Mansouri A, Simeone A, Boncinelli E, Gruss P (1996) Dentate gyrus formation requires Emx2. Development 122:3893-3898.

Pencea V, Bingaman KD, Freedman LJ, Luskin MB (2001) Neurogenesis in the subventricular zone and rostral migratory stream of the neonatal and adult primate forebrain. Exp Neurol 172:1-16.

Peretto P, Merighi A, Fasolo A, Bonfanti L (1997) Glial tubes in the rostral migratory stream of the adult rat. Brain Res Bull 42:9-21.

Peretto P, Merighi A, Fasolo A, Bonfanti L (1999) The subependymal layer in rodents: a site of structural plasticity and cell migration in the adult mammalian brain. Brain Res Bull 49:221-243.

Reynolds BA, Weiss S (1992) Generation of neurons and astrocytes from isolated cells of the adult mammalian central nervous system. Science 255:1707-1710.

Saino-Saito S, Berlin R, Baker H (2003) Dlx-1 and Dlx-2 expression in the adult mouse brain: relationship to dopaminergic phenotypic regulation. J Comp Neurol 461:18-30.

Scholzen T, Gerdes J (2000) The Ki-67 protein: from the known and the unknown. J Cell Physiol 182:311-322.

Scholzen T, Endl E, Wohlenberg C, van der Sar S, Cowell IG, Gerdes J, Singh PB (2002) The Ki-67 protein interacts with members of the heterochromatin protein 1 (HP1) family: a potential role in the regulation of higherorder chromatin structure. J Pathol 196:135-144.

Schulte D, Furukawa T, Peters MA, Kozak CA, Cepko CL (1999) Misexpression of the Emx-related homeobox genes cVax and mVax2 ventralizes the retina and perturbs the retinotectal map. Neuron 24:541-553.

Stenman J, Toresson H, Campbell K (2003) Identification of two distinct progenitor populations in the lateral ganglionic eminence: implications for striatal and olfactory bulb neurogenesis. J Neurosci 23:167-174.

Taglialatela P, Soria JM, Caironi V, Moiana A, Bertuzzi S (2004) Compromised generation of GABAergic neurons in the brains of $\mathrm{Vaxl}^{-1-}$ mice. Development 131:4239-4249.

Take-uchi M, Clarke JD, Wilson SW (2003) Hedgehog signalling maintains the optic stalk-retinal interface through the regulation of Vax gene activity. Development 130:955-968.

Tang DG, Tokumoto YM, Raff MC (2000) Long-term culture of purified postnatal oligodendrocyte precursor cells. Evidence for an intrinsic maturation program that plays out over months. J Cell Biol 148:971-984.

Tramontin AD, Garcia-Verdugo JM, Lim DA, Alvarez-Buylla A (2003) Postnatal development of radial glia and the ventricular zone (VZ): a continuum of the neural stem cell compartment. Cereb Cortex 13:580-587.

Weissman IL, Anderson DJ, Gage F (2001) Stem and progenitor cells: origins, phenotypes, lineage commitments, and transdifferentiations. Annu Rev Cell Dev Biol 17:387-403.

Wichterle H, Garcia-Verdugo JM, Alvarez-Buylla A (1997) Direct evidence for homotypic, glia-independent neuronal migration. Neuron 18:779-791.

Yoshida M, Suda Y, Matsuo I, Miyamoto N, Takeda N, Kuratani S, Aizawa S (1997) Emx1 and Emx2 functions in development of dorsal telencephalon. Development 124:101-111. 